\title{
Analisis Pengukuran Produktivitas Dengan Menggunakan Metode Mundel dan APC Di PT X
}

\author{
M. M. Manullang
}

\begin{abstract}
Abstrak - PT X merupakan perusahaan yang memproduksi komponen kendaraan roda dua dan roda empat. Perusahaan berupaya untuk meningkatkan kinerjanya dan mendapatkan keuntungan dengan meningkatkan produktivitas perusahaan. Sebelum meningkatkan produktivitas perlu dilakukan pengukuran produktivitas untuk mengetahui bagaimana kondisi produktivitas perusahaan. Untuk mengetahui tingkat produktivitas PT X maka dilakukan pengukuran produktivitas dengan menggunakan model Marvin E Mundel dan American Productivity Center (APC). Pada pengukuran ini dilakukan pada input material, energi, tenaga kerja, modal dan input total. Data yang diperlukan untuk analisis produktivitas ini diambil dari bulan april-september 2018, bulan april sebagai periode dasar dan bulan mei-september sebagai periode pengukuran. Dari hasil perhitungan produktivitas menunjukkan adanya peningkatan dan penurunan produktivitas, dimana dengan menggunakan model mundel indeks produktivitas total perusahaan pada bulan mei sebesar $104,90 \%(+4,90)$, bulan juni sebesar $101,09 \%$ $(+1,09)$, bulan juli sebesar $106,08 \%(+6,08)$, bulan agustus sebesar $104,97 \%(+4,97)$ dan bulan september sebesar $106,84 \%$ $(+6,84)$. Sementara dengan menggunakan model APC indeks produktivitas total perusahaan pada bulan mei sebesar $101,46 \%(+1,46)$, bulan juni sebesar $98,11 \%(-1,84)$, bulan juli sebesar $99,83 \%(-0,17)$, bulan agustus sebesar $99,78 \%(-$ $0,22)$ dan bulan september sebesar 101,52\% (+1,52). Berdasarkan hasil perbandingan kedua model tersebut maka perusahaan dapat memilih model mundel karena memberikan hasil perhitungan yang lebih spesifik dibandingkan model APC.
\end{abstract}

Kata Kunci- Produktivitas, Marvin E Mundel, American Productivity Center (APC)

Abstract - PT X is a company that produces two-wheeled and four-wheeled vehicle components. The company appreciates to improve its performance and gain profits by increasing company productivity. Before increasing productivity it is necessary to measure productivity to find out how to increase company productivity. To determine the productivity level of PT X, productivity measurements were carried out using the Marvin E Mundel and American Productivity Center (APC) models. This measurement is carried out on material inputs, energy, labor, capital and total inputs. The data needed for productivity analysis was taken from April-September 2018, April as the basis and May-September as the measurement period. From the calculation results of the increase in the number of increases and decreases in productivity, while using the company's total productivity index mundel model in May amounted to 104.90\% (+4.90), June was 101.09\% (+1.09), July amounting to 106.08\% (+6.08), August was 104.97\% (+4.97) and September was 106.84\% (+6.84). Whereas by using the APC model the total productivity index of the company in May was 101.46\% (+1.46), June was 98.11\% (-1.84), July was 99.83\% (-0.17), August was 99.78\% (-0.22) and September was 101.52\% (+1.52). Based on the results of choosing this second model, the company can choose the mundel model because it provides more specific calculation results than the APC model.

Keywords-Productivity, Marvin E Mundel, American Productivity Center (APC)

\section{PENDAHULUAN}

$P_{1}$ erkembangan dunia industri pada saat ini setiap perusahaan berusaha untuk selalu merencanakan dan mengembangkan strategi guna memperbaiki kinerjanya dan mempertahankan eksistensinya. Perusahaan dituntut untuk harus melakukan perbaikan-perbaikan di berbagai sektor agar perusahaan dapat menghasilkan keuntungan yang akan membuat perusahaan berkembang dan bukan hanya bertahan hidup saja. Produktivitas sangat penting bagi perusahaan dalam rangka persaingan bisnis yang sangat kompetitif. Pertumbuhan perusahaan bergantung pada kinerja, efektifitas dan efesiensi sumber daya yang dilibatkan dalam usaha.

Marco Marcelino Manullang, Mahasiswa Teknik Industri, Universitas Indraprasta PGRI, Jakarta. (Marco.marcelino66@gmail.com).
Produktivitas adalah suatu pendekatan interdisipliner untuk menentukan tujuan yang efektif, pembuatan rencana, aplikasi penggunaan cara yang produktivitas untuk menggunakan sumber-sumber secara efisien dan tetap menjaga adanya kualitas yang tinggi [1]. Produktivitas merupakan perbandingan efektifitas menghasilkan keluaran (output) dengan efisiensi penggunaan sumber-sumber masukan (input) [2][5].

PT X merupakan perusahaan yang bergerak di bidang stamping manufacturing yang memproduksi komponen kendaraan roda dua dan roda empat. Perusahaan tidak mengetahui bagaimana produktivitas yang diperoleh karena belum pernah melakukan analisis pengukuran produktivitas pada sumber dayanya. Analisis pengukuran produktivitas dilakukan untuk menunjukkan suatu kinerja dengan memperhatikan sumber daya yang digunakan. 
Penelitian pengukuran produktivitas dengan menggunakan model marvin e mundel dan american productivity center sebelumnya pernah dilakukan oleh Masharyono (2012) pada bagian pabrikasi PG. Madubaru Madukismo [4].

Penelitian ini dilakukan untuk mengetahui bagaimana produktivitas perusahaan, apakah sumber daya yang digunakan sudah optimal. Penelitian ini menggunakan metode pengukuran produktivitas model marvin e mundel dan model american productivity center (APC). Peneliti ingin membandingkan hasil perhitungan produktivitas dari kedua metode tersebut, berdasarkan perbandingan kedua model tersebut maka perusahaan dapat memilih model pengukuran produktivitas yang akan digunakan untuk menghitung produktivitas perusahaan.

\section{Metode Penelitian}

Metodologi penelitian merupakan langkahlangkah yang dilakukan untuk mengukur tingkat produktivitas di PT. X dengan menggunakan metode marvin e mundel dan american productivity center. Langkah penelitian dapat dilihat pada Gambar 1.

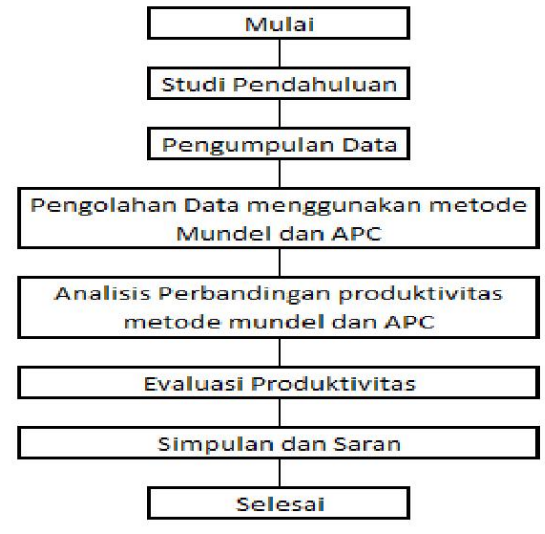

Gambar 1. Langkah-Langkah Penelitian

1. Studi Pendahuluan

Studi Pendahluan dilakukan dengan mencari sumber-sumber literatur dari buku, jurnal dan skripsi yang berhubungan dengan penelitian. Tujuan dari sumber-sumber ini adalah agar mendapatkan pemahaman secara teoritis yang berkaitan dengan pokok bahasan dalam penelitian.

\section{Pengumpulan Data}

Pengumpulan data dilakukan dengan melakukan observasi langsung ke lapanagan dan wawancara. Data yang digunakan dalam penelitian ini yaitu: a. Jumlah Produksi Periode April-September 2018

b. Jumlah Tenaga Kerja Periode April-September 2018

c. Jumlah Penggunaan Energi Periode AprilSeptember 2018

d. Jumlah Penggunaan Material Periode AprilSeptember 2018

e. Jumlah Penggunaan Modal Periode AprilSeptember 2018

3. Pengolahan Data

Pengolahan data dilakukan untuk mengetahui besarnya tingkat produktivitas perusahaan.

a. Marvin E Mundel

Marvin E. Mundel memperkenalkan penggunaan angka indeks produktivitas pada tingkat perusahaan berdasarkan dua bentuk pengukuran. Dari dua bentuk pengukuran indeks produktivitas yang dikemukakan oleh Mundel, tampak bahwa pada dasarnya kedua bentuk pengukuran itu serupa, sehingga kita dapat menggunakan salah satu dalam penerapan pengukuran produktivitas pada tingkat perusahaan [3]. Berikut langkahlangkah pengukuran model marvin e mundel:

1) Perhitungan Harga Konstan

Harga berlaku yang ada di konstankan dengan nilai deflator. Deflator didapatkan dari data inflasi badan pusat statistik (BPS). Harga konstan ini dapat dihitung menggunakan rumus:

Harga Konstan $=\frac{\text { Nilai Periode yang Bersangkuton } \times 100}{100 \mid \text { Deflatar }}$

2) Perhitungan Resource Input Partial

Perhitungan total resources input partial yang merupakan penjumlahan dari seluruh input dengan harga konstan yang terdiri dari masukan biaya material, tenaga kerja, energi dan modal.

Resources Input Partial = Biaya Material + Biaya Tenaga Kerja + Biaya Energi + Biaya Modal

3) Perhitungan Agregat Output Partial

Perhitungan agregat output dilakukan untuk mengetahui hasil output produksi maka digunakan rumus:

Agregat Output Partial $=$ Jumlah Produksi Clip $x$ Harga Jual Clip 
4) Perhitungan Indeks Produktivitas Parsial dan Indeks Produktivitas Total

Perhitungan indeks produktivitas parsial dengan membandingkan nilai indeks salah satu input (biaya material, tenaga kerja, depresiasi, energi, maintenence) terhadap keluaran (output) yang dihasilkan perusahaan. Sementara indeks Produktivitas total membandingkan total keseluruhan input terhadap keluaran (output) yang dihasilkan. Berikut merupakan rumus perhitungan indeks produktivitas marvin e mundel:

$$
\begin{aligned}
\text { Indeks Produktivitas } & =\frac{\text { Indeks Kinerja Periode Pengukuran }}{\text { Indeks Kinerja Periode Dasar }} \times 100 \\
& =\frac{A O M P / \text { RIMP }}{A O B P / \text { IBP }} \times 100 \\
\text { Indeks Produktivitas } & =\frac{\text { Indeks Output }}{\text { Indeks Input }} \times 100 \\
& =\frac{A O M P / \text { IIMP }}{A O B P / \text { RIBP }} \times 100
\end{aligned}
$$

\section{b. American Productivity Center}

Model American Productivity Center menyatakan bahwa kuantitas output dan input setiap tahun digandakan dengan harga-harga tahun dasar untuk menghasilkan indeks produktivitas. Sedangkan kuantitas output dan input setiap tahun digandakan dengan hargaharga pada tahun yang berlaku menghasilkan indeks profitabilitas. Harga-harga dan biayabiaya per unit setiap tahun digandakan dengan kuantitas output dan input pada tahun berlaku akan menghasilkan indeks perbaikan harga [4]. Berikut langkah-langkah pengukuran model american productivity center:

1) Perhitungan Indeks Produktivitas

Perhitungan indeks produktivitas menggandakan input-input yang digunakan dengan harga periode dasar, kemudian membandingkan output yang dihasilkan dengan biaya input berdasarkan harga periode dasar.

$$
\begin{aligned}
\text { Indeks Produktivitos } & =\frac{\text { Hasil Penjualan Produk }}{\text { Biaya-biaya yang dikeluarkan }} \\
& =\frac{\text { Banyaknya Output } x \text { harga jual }}{\text { Banyaknya input } x \text { harga input }}
\end{aligned}
$$

2) Perhitungan Indeks Profitabilitas

Perhitungan indeks profitabilitas menggandakan input-input yang digunakan dengan harga periode yang berlaku, kemudian membandingkan output yang dihasilkan dengan biaya input berdasarkan harga periode berlaku.

$$
\begin{aligned}
\text { Indeks Profitabilitas } & =\frac{\text { Hasil Penjualan Produk }}{\text { Biaya-biaya yang dikeluarkan }} \\
& =\frac{\text { Banyaknya Output } x \text { harga jual }}{\text { Banyaknya input } x \text { harga input }}
\end{aligned}
$$

3) Perhitungan Indeks Perbaikan Harga

Perhitungan indeks perbaikan harga menunjukan perubahan dalam biaya input terhadap harga output perusahaan.

Indeks Perbaikan Harga $=\frac{\text { Indeks Profitabilitas }}{\text { Indeks Produktivitas }}$

4. Analisis Perbandingan Produktivitas

Berdasarkan hasil dari perhitungan pengukuran produktivitas perusahaan, langkah selanjutnya yaitu melakukan analisis perbandingan produktivitas. Analisis ini dilakukan agar perusahaan dapat menentukan model pengukuran yang akan digunakan.

5. Evaluasi Produktivitas

Evaluasi produktivitas dilakukan untuk meningkatkan produktivitas perusahaan, sehingga perusahaan menjadi lebih produktif dan mendapatkan keuntungan yang lebih besar.

Penelitian ini membandingkan dua metode antara model marvin e mundel dan american productivity center, perbandingan ini dilakukan untuk mengetahui metode mana yang akan dipilih untuk digunakan oleh perusahaan. Perusahaan menginginkan tingkat produktivitas yang terbaik agar menjadi acuan untuk periode selanjutnya. Berikut merupakan hasil dan pembahasan penelitian ini:

1. Model Marvin E Mundel

Berikut ini merupakan hasil dari perhitungan model marvin e mundel. Indeks produktivitas total diperoleh dari perbandingan antara seluruh output dengan input (material, energi, tenaga kerja langsung dan modal).

Tabel 1. Hasil Perhitungan Indeks Produktivitas

\begin{tabular}{ccccccc}
\hline \multirow{2}{*}{ Input } & \multicolumn{6}{c}{ Bulan } \\
\cline { 2 - 6 } & April & Mei & Juri & Juli & Agustus & September \\
\hline Metal Sheet & $100,00 \%$ & $97,70 \%$ & $97,30 \%$ & $95,12 \%$ & $94,17 \%$ & $94,24 \%$ \\
Alfasol & $100,00 \%$ & $101,77 \%$ & $101,37 \%$ & $102,84 \%$ & $101,82 \%$ & $101,90 \%$ \\
Plastik & $100,00 \%$ & $104,56 \%$ & $104,32 \%$ & $108,91 \%$ & $107,70 \%$ & $107,72 \%$ \\
Energi & $100,00 \%$ & $102,91 \%$ & $100,44 \%$ & $105,62 \%$ & $104,61 \%$ & $105,61 \%$ \\
Tenaga Keja Langsung & $100,00 \%$ & $109,42 \%$ & $101,76 \%$ & $110,75 \%$ & $109,51 \%$ & $114,75 \%$ \\
Modal & $100,00 \%$ & $104,29 \%$ & $100,40 \%$ & $105,70 \%$ & $104,58 \%$ & $105,33 \%$ \\
Total & $100,00 \%$ & $104,90 \%$ & $101,09 \%$ & $106,08 \%$ & $104,97 \%$ & $106,84 \%$ \\
\hline
\end{tabular}


Berdasarkan tabel diatas dapat dilihat bahwa indeks produktivitas parsial input metal sheet mengalami penurunan produktivitas namun indeks produktivitas parsial input alfasol, plastik, energi, tenaga kerja langsung dan modal mengalami kenaikan produktivitas. Sehingga indeks produktivitas total perusahaan mengalami peningkatan, indeks produktivitas total tertinggi terjadi pada bulan september sebesar 106,84\% dan indeks produktivitas total terendah terjadi pada bulan juni sebesar 101,90\%.

\section{Model American Productivity Center}

Berikut ini merupakan hasil perhitungan model american productivity center.

Hasil perhitungan Indeks produktivitas didapatkan dengan terlebih dahulu menggandakan input yang digunakan dengan harga periode dasar (harga bulan april). Berikut ini merupakan hasil perhitungan indeks produktivitas.

Tabel 2. Hasil Perhitungan Indeks Produktivitas

\begin{tabular}{ccccccc}
\hline \multirow{2}{*}{ Input } & \multicolumn{6}{c}{ Bulan } \\
\cline { 2 - 7 } & April & Mei & Jumi & Juli & Agustus & September \\
\hline Bahan Baku & $100,00 \%$ & $100,02 \%$ & $100,01 \%$ & $100,00 \%$ & $100,00 \%$ & $100,00 \%$ \\
Energi & $100,00 \%$ & $101,28 \%$ & $99,22 \%$ & $100,05 \%$ & $100,10 \%$ & $100,97 \%$ \\
Tenaga Kerja Langsung & $100,00 \%$ & $104,56 \%$ & $97,61 \%$ & $101,86 \%$ & $101,75 \%$ & $106,53 \%$ \\
Modal & $100,00 \%$ & $99,66 \%$ & $96,30 \%$ & $97,22 \%$ & $97,16 \%$ & $97,78 \%$ \\
Total & $100,00 \%$ & $101,46 \%$ & $98,11 \%$ & $99,83 \%$ & $99,78 \%$ & $101,52 \%$ \\
\hline
\end{tabular}

Berdasarkan tabel diatas dapat dilihat bahwa indeks produktivitas parsial input energi dan tenaga kerja langsung mengalami penuruan pada bulan juni, sementara input modal mengalami penurunan pada setiap periodenya. Hal ini menyebabkan indeks produktivitas total perusahaan mengalami peningkatan dan penuruan, indeks produktivitas total tertinggi terjadi pada bulan september sebesar $101,52 \%$ dan indeks produktivitas total terendah terjadi pada bulan juni sebesar $98,11 \%$.

Hasil perhitungan indeks profitabilitas didapatkan dengan terlebih dahulu menggandakan input yang digunakan dengan harga periode yang berlaku (harga sesuai bulan tersebut). Berikut merupakan hasil perhitungan indeks profitabilitas.

Tabel 3. Hasil Perhitungan Indeks Profitabilitas

\begin{tabular}{ccccccc}
\hline \multirow{2}{*}{ Input } & \multicolumn{6}{c}{ Bulan } \\
\cline { 2 - 7 } & April & Mei & Juni & Juli & Agustus & September \\
\hline Bahan Baku & $100,00 \%$ & $100,53 \%$ & $100,51 \%$ & $100,98 \%$ & $100,98 \%$ & $100,98 \%$ \\
Energi & $100,00 \%$ & $105,03 \%$ & $102,89 \%$ & $107,46 \%$ & $107,51 \%$ & $108,45 \%$ \\
Tenaga Kerja Langsung & $100,00 \%$ & $108,43 \%$ & $101,22 \%$ & $109,41 \%$ & $109,28 \%$ & $114,42 \%$ \\
Modal & $100,00 \%$ & $103,35 \%$ & $99,87 \%$ & $104,42 \%$ & $104,36 \%$ & $105,03 \%$ \\
Total & $100,00 \%$ & $104,05 \%$ & $100,65 \%$ & $104,90 \%$ & $104,85 \%$ & $106,63 \%$ \\
\hline
\end{tabular}

e-ISSN 2657-0181

Berdasarkan tabel diatas dapat dilihat bahwa indeks profitabilitas input modal mengalami penurunan pada bulan juni sementara input lain mengalami peningkatan. Hal ini menyebabkan indeks profitabilitas total perusahaan mengalami peningkatan dan penuruan, indeks produktivitas total tertinggi terjadi pada bulan september sebesar $106,63 \%$ dan indeks produktivitas total terendah terjadi pada bulan juni sebesar $100,65 \%$.

\section{HASIL DAN PEMBAHASAN}

Hasil perhitungan indeks perbaikan harga didapatkan dengan membandingkan indeks profitabilitas dengan indeks perbaikan harga. Berikut merupakan hasil perhitungan indeks perbaikan harga

Tabel 4. Hasil perhitungan Indeks Perbaikan Harga

\begin{tabular}{ccccccc}
\hline \multirow{2}{*}{ Input } & \multicolumn{6}{c}{ Bulan } \\
\cline { 2 - 6 } & April & Mei & Juni & Juli & Agustus & September \\
\hline Bahan Baku & $100,00 \%$ & $100,51 \%$ & $100,51 \%$ & $100,98 \%$ & $100,98 \%$ & $100,98 \%$ \\
Energi & $100,00 \%$ & $103,70 \%$ & $103,70 \%$ & $107,41 \%$ & $107,41 \%$ & $107,41 \%$ \\
Tenaga Keja Langsung & $100,00 \%$ & $103,70 \%$ & $103,70 \%$ & $107,41 \%$ & $107,41 \%$ & $107,41 \%$ \\
Modal & $100,00 \%$ & $103,70 \%$ & $103,70 \%$ & $107,41 \%$ & $107,41 \%$ & $107,41 \%$ \\
Total & $100,00 \%$ & $102,55 \%$ & $102,59 \%$ & $105,08 \%$ & $105,08 \%$ & $105,04 \%$ \\
\hline
\end{tabular}

Berdasarkan tabel diatas dapat dilihat bahwa indeks perbaikan harga mengalami peningkatan pada semua jenis input disetiap periodenya sehingga menyebabkan produktivitas dan profitabilitas perusahaan mengalami penurunan.

3. Analisis Perbandingan Produktivitas

Analisis Perbandingan Model Marvin E Mundel dan American Productivity Center, terdapat perbedaan hasil perhitungan Indeks Produktivitas pada kedua model, dikarenakan model American Productivity Center melihat secara total dari masing-masing input. Sedangkan Model Marvin E Mundel melihat Input secara mandiri atau masing-masing, adanya perbandingan dari kedua model tersebut dapat dilihat pada Tabel 5.

Berdasarkan tabel perbandingan indeks produktivitas diatas, model pengukuran marvin e mundel menunjukan terjadinya penurunan indeks produktivitas pada input metal sheet di setiap periodenya tetapi pada input alfasol, plastik, energi, tenaga kerja dan modal mengalami peningkatan indeks produktivitas pada setiap periodenya sehingga indeks produktivitas total perusahaan mengalami peningkatan, berdasarkan hasil perhitungan indeks produktivitas total perusahaan pada bulan mei didapatkan sebesar 
$104,90 \%(+4,90)$, bulan juni didapatkan sebesar $101,09 \%(+1,09)$, bulan juli didapatkan sebesar $106,08 \% \quad(+6,08)$, bulan agustus didapatkan sebesar $104,97 \%(+4,97)$ dan bulan september didapatkan sebesar $106,84 \%(+6,84)$. Sementara berdasarkan pengukuran model american productivity center menunjukan terjadinya penurunan indeks produktivitas pada input modal disetiap periodenya dan input energi dan tenaga kerja pada bulan juni tetapi pada input material mengalami peningkatan indeks produktivitas pada setiap periodenya, input energi dan tenaga kerja mengalami peningkatan indeks produktivitas pada bulan mei, juli, agustus september. Sehingga indeks produktivitas total perusahaan mengalami peningkatan dan penurunan, berdasarkan hasil perhitungan indeks produktivitas total perusahaan pada bulan mei didapatkan sebesar 101,46\% $(+1,46)$, bulan juni didapatkan sebesar 98,11\% ($1,84)$, bulan juli didapatkan sebesar 99,83\% ($0,17)$, bulan agustus didapatkan sebesar 99,78\% ($0,22)$ dan bulan september didapatkan sebesar $101,52 \%(+1,52)$.

Tabel 5. Perbandingan Indeks Produktivitas Mundel dan APC

\begin{tabular}{|c|c|c|c|c|c|c|c|c|c|c|c|c|c|}
\hline \multirow{2}{*}{\multicolumn{2}{|c|}{ Input }} & \multicolumn{2}{|c|}{ April } & \multicolumn{2}{|c|}{ Mei } & \multicolumn{2}{|c|}{ Juni } & \multicolumn{2}{|c|}{ Juli } & \multicolumn{2}{|c|}{ Agustus } & \multicolumn{2}{|c|}{ September } \\
\hline & & Mundel & APC & Mundel & APC & Mundel & APC & Mundel & APC & Mundel & APC & Mundel & APC \\
\hline \multirow{3}{*}{ Material } & $\begin{array}{l}\text { Metal } \\
\text { Shest }\end{array}$ & $100,00 \%$ & \multirow{3}{*}{$100,00 \%$} & $97,70 \%$ & \multirow{3}{*}{$100,02 \%$} & $97,30 \%$ & \multirow{3}{*}{$100,01 \%$} & $95,12 \%$ & \multirow{3}{*}{$100,00 \%$} & $94,17 \%$ & \multirow{3}{*}{$100,00 \%$} & $94,24 \%$ & \multirow{3}{*}{$100,00 \%$} \\
\hline & Alfasol & $100,00 \%$ & & $101,77 \%$ & & $101,37 \%$ & & $102,84 \%$ & & $101,82 \%$ & & $101,90 \%$ & \\
\hline & Plastik & $100,00 \%$ & & $104,56 \%$ & & $104,32 \%$ & & $108,91 \%$ & & $107,70 \%$ & & $107,72 \%$ & \\
\hline \multicolumn{2}{|c|}{ Energi } & $100,00 \%$ & $100,00 \%$ & $102,91 \%$ & $101,28 \%$ & $100,44 \%$ & $99,22 \%$ & $105,62 \%$ & $100,05 \%$ & $104,61 \%$ & $100,10 \%$ & $105,61 \%$ & $100,97 \%$ \\
\hline \multicolumn{2}{|c|}{ Tenaga Kerja } & $100,00 \%$ & $100,00 \%$ & $109,42 \%$ & $104,56 \%$ & $101,76 \%$ & $97,61 \%$ & $110,75 \%$ & $101,86 \%$ & $109,51 \%$ & $101,75 \%$ & $114,75 \%$ & $106,53 \%$ \\
\hline \multicolumn{2}{|c|}{ Modal } & $100,00 \%$ & $100,00 \%$ & $104,29 \%$ & $99,66 \%$ & $100,40 \%$ & $96,30 \%$ & $105,70 \%$ & $97,22 \%$ & $104,58 \%$ & $97,16 \%$ & $105,33 \%$ & $97,78 \%$ \\
\hline \multicolumn{2}{|c|}{ Total } & $100,00 \%$ & $100,00 \%$ & $104,90 \%$ & $101,46 \%$ & $101,09 \%$ & $98,11 \%$ & $106,08 \%$ & $99,83 \%$ & $104,97 \%$ & $99,78 \%$ & $106,84 \%$ & $101,52 \%$ \\
\hline
\end{tabular}

4. Evaluasi Produktivitas

Mengevaluasi tingkat produktivitas yang menurun menggunakan Fishbone Diagram untuk mencari faktor-faktor penyebab terjadinya penyimpangan kualitas hasil kerja. Berikut merupakan hasil analisis faktor-faktor yang mempengaruhi menurunnya produktivitas perusahaan.

\section{a. Tenaga Kerja}

Kurangnya kesadaran para pekerja terhadap pentingnya ketepatan waktu dalam menyelesaikan produk menyebabkan sering terjadinya target produksi tidak tercapai.

b. Material

Tingginya biaya bahan baku disebabkan oleh banyaknya material yang terbuang dan kenaikan harga bahan baku sehingga menyebabkan perusahaan harus mengalami beban (biaya) produksi yang tinggi.

c. Modal

Besarnya pengeluaran menyebabkan biaya modal membesat sehingga mempengaruhi penurunan produktivitas perusahaan. d. Energi

Penggunaan energi yang belebih menyebabkan biaya energi menjadi tinggi sehingga mempengaruhi penurunan produktivitas perusahaan.

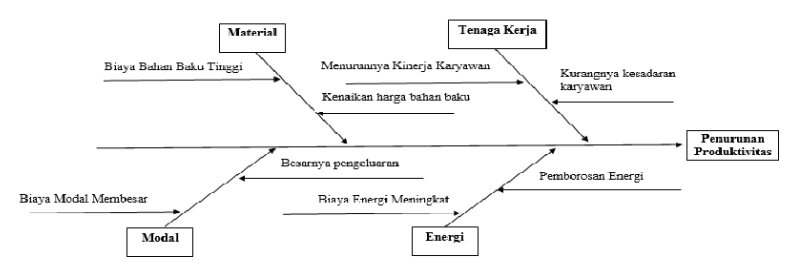

Gambar 2. Fishbone Diagram

\section{SIMPULAN}

1. Berdasarkan hasil perhitungan terjadinya peningkatan dan penurunan produktivitas, dimana dengan menggunakan model mundel indeks produktivitas total perusahaan pada bulan mei sebesar 104,90\% $(+4,90)$, bulan juni sebesar $101,09 \%(+1,09)$, bulan juli sebesar 106,08\% $(+6,08)$, bulan agustus sebesar 104,97\% $(+4,97)$ dan bulan september sebesar 106,84\% $(+6,84)$. Sementara dengan menggunakan model APC indeks produktivitas total perusahaan pada bulan mei sebesar 101,46\% $(+1,46)$, bulan juni sebesar $98,11 \%(-1,84)$, bulan juli sebesar 99,83\% $(-0,17)$, 
bulan agustus sebesar 99,78\% $(-0,22)$ dan bulan september sebesar $101,52 \%(+1,52)$.

2. Berdasarkan hasil perhitungan kedua model ini terdapat perbedaan indeks produktivitas perusahaan, dimana dengan menggunakan model APC terjadi penurunan indeks produktivitas pada input energi, tenaga kerja dan modal. Sementara dengan menggunakan model mundel terjadi penurunan indeks produktivitas pada input metal sheet.

3. Berdasarkan hasil perbandingan kedua metode, maka metode yang lebih sesuai untuk digunakan perusahaan adalah model mundel karena dengan menggunakan model ini perusahaan dapat melihat penurunan atau peningkatan produktivitas secara spesifik.

4. Saran untuk PT X agar lebih mengoptimalkan penggunaan sumber daya yang digunakan dan memperhatikan kenaikan harga input agar perusahaan mengalami kenaikan produktivitas.

5. Saran untuk penelitian yang akan datang untuk tidak hanya melakukan perbandingan namun melakukan peningkatan produktivitas perusahaan.

\section{REFERENSI}

[1] M. Sinungan, Produktivitas Apa dan Bagaimana. Jakarta: Bumi Aksara, 2015.

[2] A. Komang, dkk. Manajemen Sumber Daya Manusia. Yogyakarta: Graha Ilmu, 2012.

[3] V. Gasperz. Manajemen Produktivitas Total. Jakarta: Gramedia Pustaka Utama. 2000.

[4] Masharyon. Analisis Pengukuran Produktivitas Dengan Model The American Productivity Center (APC) Dan Marvin E. Mundel Pada Bagian Pabrikasi PG. Madukismo. Yogyakarta: Program Studi Teknik Industri Universitas Islam Negeri Sunan Kalijaga. 2012

[5] A. Bakar, dkk. Usulan Peningkatan Produktivitas Berdasarkan Metode Marvin E. Mundel dan American Productivity Center Di PT. Raffsya Media. Jurnal: Journal of Industrial Engineering Management, 2 (2), hlm 1-13. 2017. 